\title{
Acute Reversible Contralateral Renal Failure after Unilateral Renal Artery Reconstruction*
}

\author{
J. F. AMMANN, M.D. ; W. A. SCHEITLIN, M.D. ; H. F. SCHWARZ, M.D.
}

Between 1962 and 1967 we noted a complication after unilateral renal artery reconstruction which to our knowledge has not yet been recorded. This was an acute reversible failure of the contralateral kidney, which occurred within a few days of operation and persisted for a few weeks before normal function returned. This complication arose in two out of 32 patients who underwent operation for renal artery stenosis (Scheitlin, 1927 ; Schwarz et al., 1967).

\section{Case 1}

The patient, a man aged 48, was normotensive up to the age of 47. In 1962 his slight chronic headache became worse, forcing him to seek medical attention. His blood pressure was 190/100 $\mathrm{mm}$. $\mathrm{Hg}$, and this level could not be reduced by hypotensive drugs. A specialist had diagnosed right renal artery stenosis, this being demonstrated both angiographically (Fig. 1) and functionally

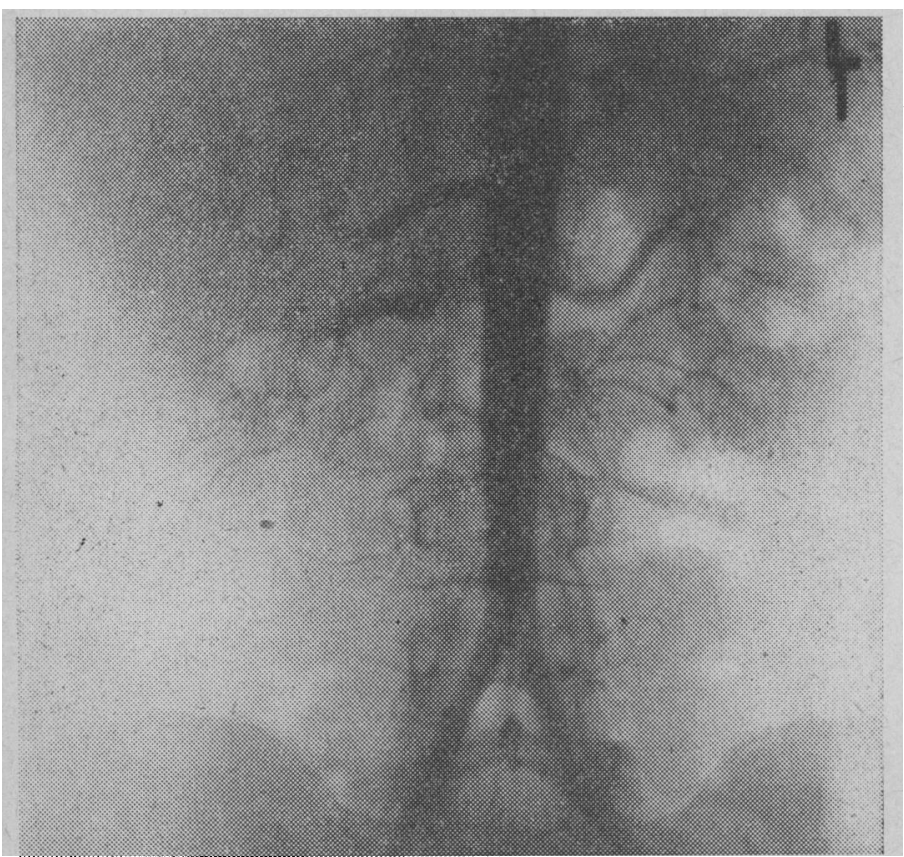

FIG. 1.-Case 1. Retrograde aortograph showing typical arteriosclerotic stenosis of the right renal artery.

(positive Howard test, positive Rapoport index). Renal function was normal, and a routine intravenous pyelogram showed an increased density of contrast medium in the right renal pelvis with good excretion on the left side.

Operation was performed under hypothermia on 29 October 1962, typical atheromatous plaques being removed from the stenotic right renal artery. The artery was closed by patch-graft from the long saphenous vein. During the operation the aorta was cross-clamped for 31 minutes so that the left renal artery was perfused. The patient made a good recovery and the postoperative blood pressure was between $140 / 80$ and $150 / 95 \mathrm{~mm}$. $\mathrm{Hg}$. The blood urea

- From the Surgical Department A and the Medical Department, Kantonsspital, Zurich. increased to $54 \mathrm{mg} / 100 \mathrm{ml}$, but by 9 November was normal (31 mg./100 ml.). He was discharged on 12 November in good condition and with a normal stable blood pressure.

On 28 November blood pressure again increased to $180 / 90$ $\mathrm{mm}$. Hg. Another intravenous pyelogram (Fig. 2a) showed that excretion of contrast medium was normal on the right (operated) side but that there was no excretion on the left. Chromocystoscopy proved the existence of left renal failure, no dye being excreted. The retrograde pyelogram showed normal appearances with no ureteral obstruction. No urine was collected by ureteral catheter. Retrograde aortography showed a normal left renal artery. In the urine sediment some waxy casts as well as a few granular casts were found. The phenolsulphonphthalein excretion was 47 and $19 \%$. The patient's general condition was good, and he was able to continue to practise as a dentist.

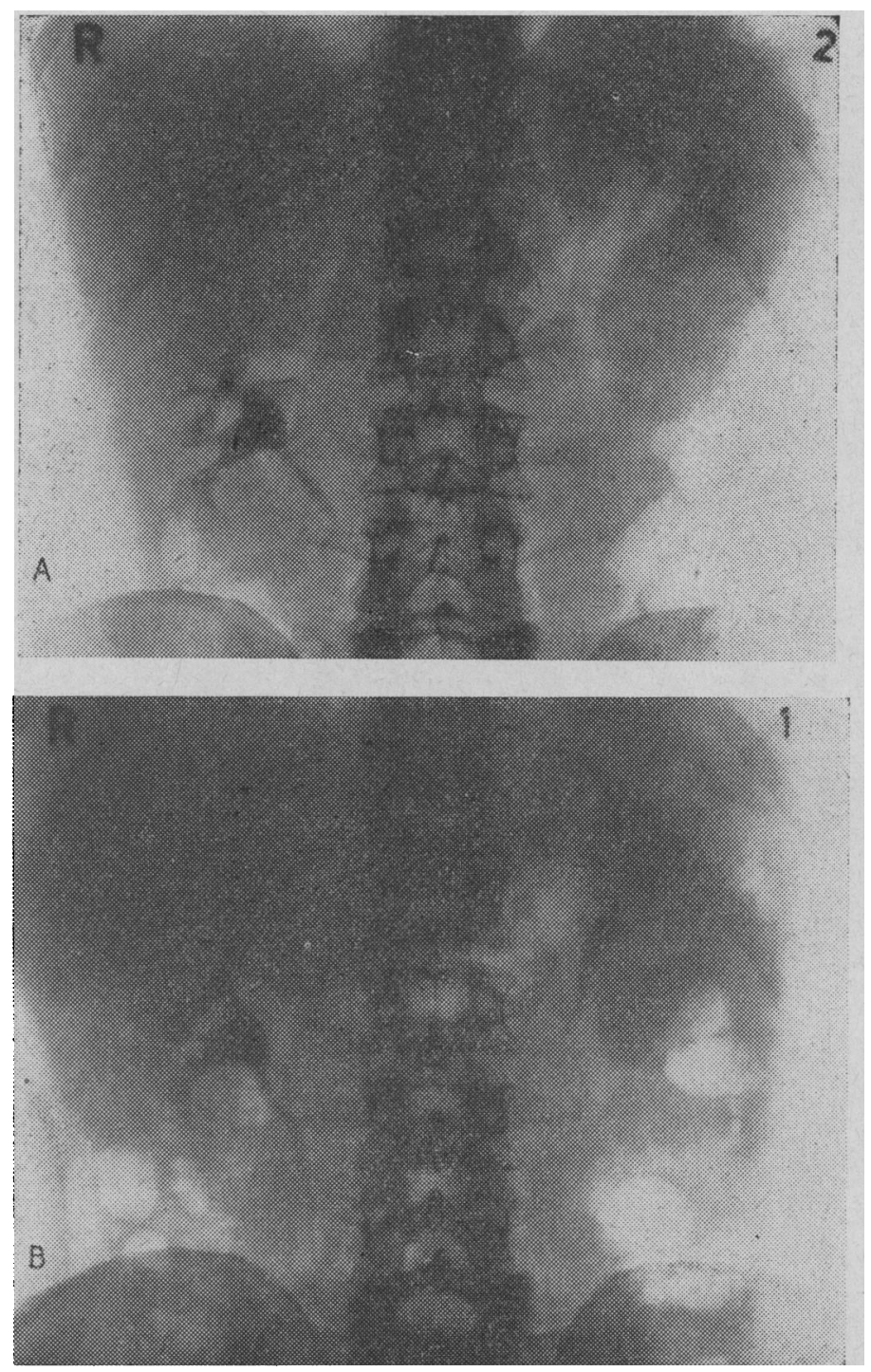

FIG. 2.-Case 1. Intravenous pyelograms: (A) 30 days postoperatively, (B) 88 days postoperatively. 
Within two months the blood pressure was normal and a control intravenous pyelogram showed only a slight reduction of contrast medium excretion on the left side. The radiographic appearances (Fig. 2b) were little changed from those preoperatively. The phenolsulphonphthalein excretion was now $58 \%$ after 35 minutes and $21 \%$ after 120 minutes.

\section{Case 2}

Eighteen months before admission to hospital the patient, a man aged 54, suffered from slight visual disturbance in his left eye. His blood pressure was 200/100 mm. Hg in July 1966, though previously it had always been found to be normal. During treatment for chronic bronchitis and bronchiectasis in another hospital an investigation of his hypertension had been undertaken. Typical signs of a right renal artery stenosis were found, and the angiographical appearances of the kidneys were consistent with the presence of stenosis (Fig. 3). An intravenous pyelogram showed symmetrical excretion of the contrast medium, the right kidney being smaller than the left one. The patient was admitted to our hospital on 22 November 1966, blood pressure then being 200/120 $\mathrm{mm}$. Hg, urea $40 \mathrm{mg} . / 100 \mathrm{ml}$, and blood creatinine $1.3 \mathrm{mg} . /$ $100 \mathrm{ml}$. Shortly before admission to hospital the phenolsulphonphthalein excretion was $21 \%$ after 15 minutes and $51 \%$ after 60 minutes.

Operation was performed under hypothermia on 28 November. The right renal artery showed a filiform narrowing. The stenosis was corrected by a patch-graft from the long saphenous vein. The aorta was cross-clamped for 77 minutes, with uninterrupted perfusion of the left renal artery. A biopsy specimen was taken from both kidneys ; subsequent histological examination showed that both had the appearances of advanced arteriosclerosis, the right kidney being apparently more affected.

The patient made a good recovery. The postoperative blood pressure was $125 / 60$ and $130 / 95 \mathrm{~mm}$. Hg. Five days later the blood urea level had increased, to $112 \mathrm{mg} . / 100 \mathrm{ml}$. The serum creatinine was $1.6 \mathrm{mg} . / 100 \mathrm{ml}$. The intravenous pyelogram was repeated on 8 December as the urea and the serum creatinine levels had not become normal (Fig. 4a). There was no excretion of the contrast medium from the left kidney-that is, on the non-operated side-and excretion was slightly decreased on the right (operated) side. Radionephrography with ${ }^{131}$ I hippurate showed good renal function on the right side and a minimal slowly increasing activity on the left. The patient was discharged on 21 Decembe: in good condition, though slight left-sided renal failure was still present. Blood pressure before discharge was $170 / 90 \mathrm{~mm}$. $\mathrm{Hg}$.

Three months later both kidneys were functioning normally. Serum urea was $36 \mathrm{mg} . / 100 \mathrm{ml}$., serum creatinine $1.2 \mathrm{mg} . / 100 \mathrm{ml}$., and the phenolsulphonphthalein excretion after 35 and 120 minutes was 42 and $68 \%$ respectively. Good symmetrical kidney function

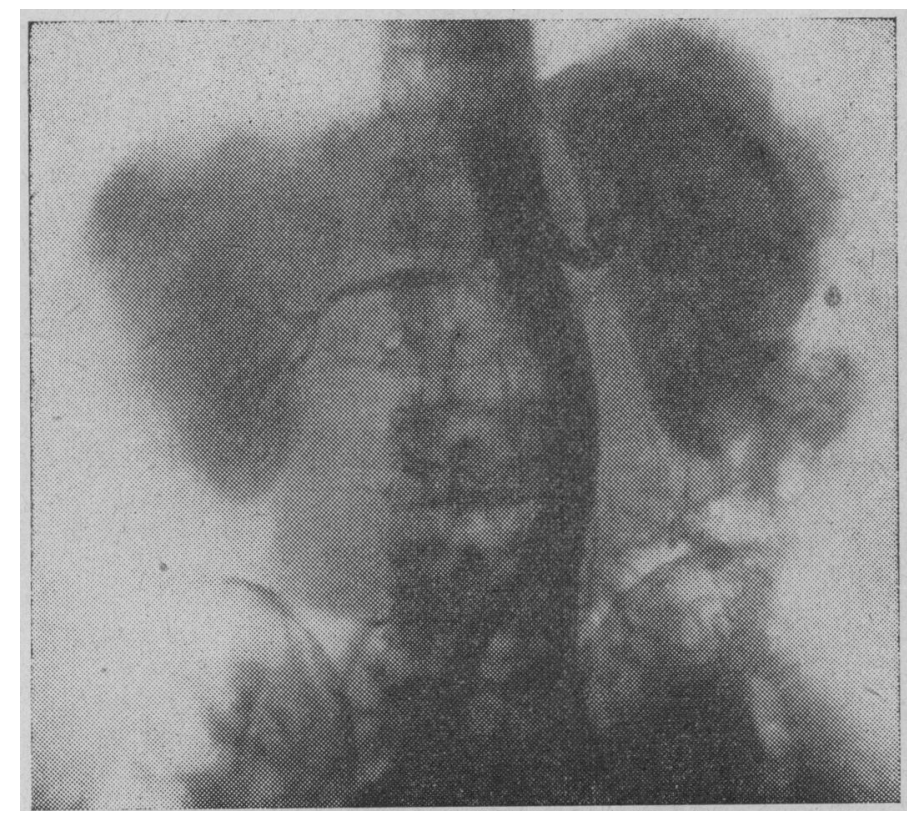

FIG. 3.-Lase 2. Retrograde aortograph showing typical arteriosclerotic stenosis of the right renal artery. was found in both the intravenous pyelogram (Fig. 4b) and radionephrography. The patient was in excellent condition, having a normal blood pressure of $120 / 60 \mathrm{~mm}$. $\mathrm{Hg}$.

\section{Discussion}

This phenomenon of failure of function in the non-operated kidney after an operation for renal stenosis had never been reported, not even in large series of cases (Morris et al., 1966).

Acute renal failure has long been known as a dreaded complication of surgical intervention on the aorta. If the aorta is cross-clamped proximal to the renal arteries for more than 30 minutes or distal to them for more than two hours, oliguria or anuria develops postoperatively (Szilagyi et al., 1959). This anuria is often fatal. Many experiments have been carried out to investigate this problem. Powers et al. (1957) were able to provoke tubular necrosis after infrarenal aortic cross-clamping in dogs, as were Nanson and Noble (1959). On the other hand, Gagnon et al. (1960), using the same procedure, did not find that tubular necrosis occurred. These workers noticed only a temporary reduction in kidney blood flow and a decrease in urine flow.

Subsequently McGonigle et al. (1961) postulated that infrarenal cross-clamping up to two hours could not lead in itself to renal failure. Additional factors were shown to be generalized hypotension or venous ischaemia of the kidney (Foster et al., 1963 ; Kountz et al., 1963). The so-called reflex anuria (Doolan et al., 1960) after infrarenal aortic cross-clamping appeared to occur as follows: Owing to cross-clamping of the aorta immedi-

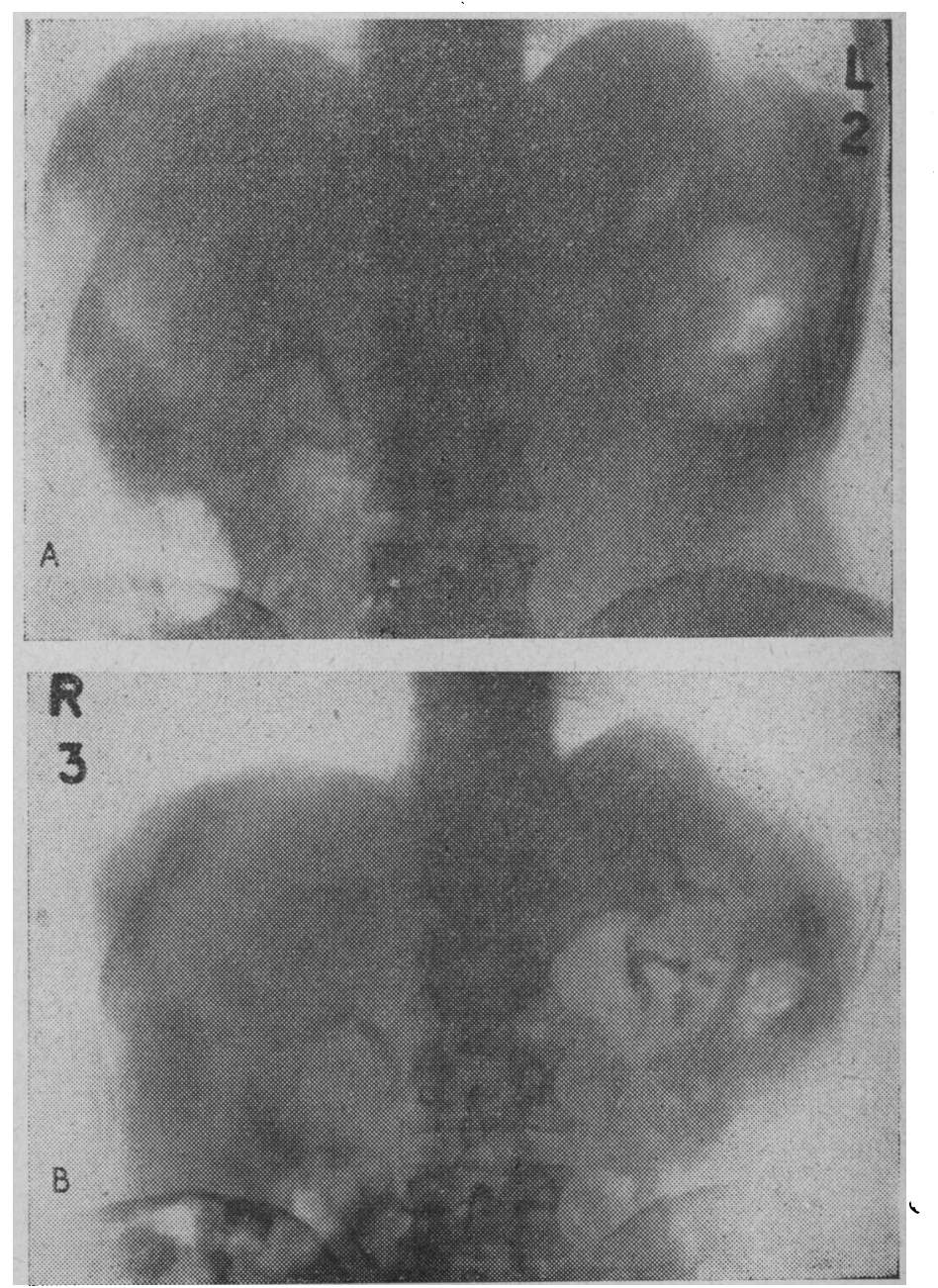

FIG. 4.-Case 2. Intravenous pyelograms: (a) 43 days postoperatively, (b) 121 days postoperatively. 
ately distal to the renal arteries the haemodynamic situation in the aorta and renal arteries is changed. The laminar blood stream becomes turbulent and the renal arteries must bear the whole resulting kinetic energy. A vasospasm of the vasa afferentia might be induced. The volume flow, already reduced by turbulence, is further reduced. Atheromatous emboli, released and dispersed from the clamped aorta (Thurlbeck and Castleman, 1957), and vasoactive substances, released by the reninangiotensin-mechanism (Kountz et al., 1963), appear to be complementary factors. If the aorta is cross-clamped distal to the renal arteries for a maximum of two hours renal function is temporarily disturbed. As was shown experimentally, tubular necrosis arises after infrarenal cross-clamping for over two hours. The frequency of this complication after aortic surgery is given as between 3.8 and $20 \%$ (Kountz et al., 1963).

Different prophylactic measures have been recommended. Nanson and Noble (1959) injected local anaesthetics and ganglion-blockers into the renal pedicle; Barry et al. (1961) gave osmotic active mannitol during operation and in the immediate postoperative phase. Finally, it was suggested that adiphenine hydrochloride or Arfonad (trimetaphan camsylate) should be injected into the renal pedicle during operation (Doolan et al., 1960).

Our two cases of acute contralateral renal failure after unilateral renal artery reconstruction were probably caused by the same mechanisms as mentioned above. During the operations on the right kidney the aorta was cross-clamped for 31 and 77 minutes respectively, the clamp being placed in both cases obliquely - that is, from the right cranial to the left caudal aspect. The blood flow to the left kidney appeared to be ensured that way. In both cases, however, turbulence in the aorta, spasms of the vasa afferentia, and resulting decrease in flow of the open renal artery obviously caused renal ischaemia and parenchymal damage.

If in unilateral renal artery reconstruction an aortic clamp is placed in such a way that the contralateral renal artery is still perfused, then damage of this kidney is possible even after a short cross-clamping time.

\section{Summary}

Two cases of contralateral acute reversible renal failure after unilatcral renovascular operation are reported. The failure was proved by intravenous pyelography, renography, and ureteral catheterization. Three months later renal function was normal again, no treatment having been necessary. Probably the same factors play a part in failure of the untouched kidney as in renal failure after aortic surgery. The haemodynamic situation in the aorta is altered when the aorta is cross-clamped immediately distal to the renal arteries. This results in renal ischaemia, and, in other cases, unilateral anuria and renal insufficiency.

Requests for reprints should be addressed to Dr. J. F. Ammann, Department of Surgery A, Kantonsspital, Zurich.

\section{REFERENCES}

Barry, K. G., et al. (1961). New Engl. 7. Med., 264, 967.

Doolan, P. D., Wiggins, R. A., Thiel, G. B., Lee, K. J., and Martinez, E. (1960). Amer. 7. Med., 28, 895.

Foster, J. H., Adkins, R. B., Chamberlain, N. O., Symbas, P. N., and Harris, A. P. (1963). f. Amer. med. Ass., 183, 451.

Gagnon, J. A., Bolt, D. A., Clarke, R. W., and Geever, E. F. (1960).

Surgery, 47, 240.
Kountz, S. L., Tuttle, K. L., Cohn, L. H., Eschelman, L. T., and Cohn, R. (1963). F. Amer. med. Ass., 183, 447.

McGonigle, D. J., Seipel, R. S., and Wylie, E. J. (1961). Surgery, 49, 235.

Morris, G. C., jun., DeBakey M. E., Crawford, E. S., Cooley, D. A., and Zanger,

Nanson, E. M., and Noble, J. G. (1959). Surgery, 46, 388.

Powers, S. R., Boba, A., and Stein, A. (1957). Surgery, 42, 156

Scheitlin, W. A. (1967). Ergebn. inn. Med. Kinderheilk., 26, 45.

Schwarz, H. F., Scheitlin, W. A., and Senning, §. (1967). Langenbecks Arch. klin. Chir., 319, 1182. Szilagyi, D. E., Smith, R. F., and Whitcomb, J. G. (1959). Arch. Surg.,

Thurlbeck, W. M., and Cas:leman, B. (1957). New Engl. ł. Med., 257, 442.

\title{
Plasma Cortisol Levels in Lung Cancer
}

\author{
IVAN LICHTER,* F.R.C.S., F.R.A.C.S. ; NANCY E. SIRETT,* B.SC., A.N.Z.I.C.
}

Brit. med. F., 1968, 2, 154-156

Lung cancer, especially the oat-cell type, may be associated with Cushing's syndrome, and in these cases the tumour produces a substance indistinguishable from pituitary corticotrophin (Liddle et al., 1965). In patients dying of lung cancer an increase in width of the adrenal cortex has been demonstrated (Sholiton et al., 1961 ; Caranasos and Ruebner, 1963). Segaloff et al. (1962) established that this was not due to the prolonged stress of the disease, as patients with non-malignant chronic pulmonary lesions showed no evidence of adrenocortical hyperactivity. Increased morning plasma 17-hydroxycorticoid levels in lung cancer were reported by Werk and Sholiton (1960). Eighteen of the 22 subjects studied had secondary deposits and some were very ill. In only a few individual patients could the level be regarded as abnormally high, though the mean levels were generally higher than those in a control series. That raised plasma corticoid levels can be expected in patients dying from a variety of illnesses was demonstrated by Sandberg et al. (1956).

\footnotetext{
* Department of Surgery and N.Z.M.R.C. Endocrinology Research Unit,
} University of Otago Medical School, Dunedin, New Zealand.
Segaloff et al. (1962) also assessed adrenal function in patients with lung cancer. Plasma corticoid levels (Porter and Silber chromogens) measured in 26 patients were found to be generally higher than in those of six control patients who had benign lung lesions. The values in this latter group were similar to those in six normal ambulatory male controls. This study was later continued by Hatch et al. (1965). They investigated 100 patients with lung cancer and Porter-Silber chromogens were again measured. Seventy-one of them had elevated plasma corticoid levels, and in 25 of these the level was above $20 \mu \mathrm{g} . / 100 \mathrm{ml}$. (4-11 $\mu \mathrm{g} . / 100 \mathrm{ml}$. was thought to be normal). Only one of these patients had Cushing's syndrome. The authors felt that an abnormally high plasma corticoid level in patients with pulmonary disease was added evidence that the lesion might be malignant. They noted that four to six weeks after surgical removal of a lung cancer the plasma corticoid levels returned to normal and the level was found to rise again with recurrence of the lung cancer.

We have undertaken this study to endeavour to assess the diagnostic and prognostic significance of the plasma cortisol 